\title{
Regeneração in vitro via organogênese direta de Bauhinia cheilantha
}

\author{
In vitro regeneration of the Bauhinia cheilantha via organogenesis
}

\author{
Ingrid Estefania Mancia de Gutiérrez ${ }^{\mathrm{I}}$ Cristina Ferreira Nepomuceno ${ }^{\mathrm{II}}$ \\ Carlos Alberto da Silva Ledo ${ }^{\mathrm{III}}$ José Raniere Ferreira de Santana ${ }^{\mathrm{IV}}$
}

\section{RESUMO}

\begin{abstract}
Bauhinia cheilantha, conhecida como "pata-devaca”, possui grande relevância econômica e etnofarmacológica no semiárido brasileiro. Nas suas sementes constatou-se dormência, o que dificulta a obtenção de plantas uniformes e em curto período de tempo, diante disso, o presente trabalho objetivou estabelecer um protocolo de micropropagação para a espécie. Os segmentos cotiledonar e nodal de plântulas emergidas in vitro foram inoculados em meio de cultura WPM, suplementado com diferentes concentrações de 6-benzilaminopurina (BAP), thidiazuron (TDZ) ou cinetina (KIN) para induzir a regeneração de brotos adventícios. Na fase de enraizamento foram testadas diferentes concentrações de ácido indol-3-butírico (AIB) e de carvão ativado. Nos segmentos nodais houve maior capacidade organogênica do que no segmento cotiledonar. O maior número de brotos $\left(4,3\right.$ e 2,1) foi obtido com 1,0mg $L^{-1}$ de TDZ e 1,5mg $L^{-1}$ de $B A P$, respectivamente. No entanto, na presença de TDZ foram observadas as menores brotações. A presença de 2,0mg $L^{-1}$ de AIB com carvão ativado (CA) promoveu a maior porcentagem de enraizamento (cerca de 60,0\%) e maior número de raízes adventícias $(2,5)$. As brotações enraizadas foram transferidas para casa de vegetação e aclimatizadas com sucesso.
\end{abstract}

Palavras-chave: micropropagação, Leguminosae, pata-devaca, citocininas, auxinas, carvão ativado.

\footnotetext{
ABSTRACT

Bauhinia cheilantha, known as "pata-de-vaca", is of great economic and ethnopharmacological importance in the semiarid Brazilian. Seeds are dormant which makes it
}

\begin{abstract}
difficult to obtain uniform plants in a short time before this, our study aimed to establish a micropropagation protocol for the species. Cotyledonary and nodal segments of seedlings grown in vitro were inoculated on Woody Plant Medium (WPM) supplemented with various concentrations of 6benzylaminopurine $(B A P)$, thidiazuron $(T D Z)$ or kinetin $(K N)$ to induce adventitious shoot regeneration. In the rooting phase, different concentrations of indole-3-butyric acid (IBA) and the activated charcoal were tested. The nodal segments showed organogenic capacity greater than the cotyledonary segment. The highest number of shoots (4.3 and 2.1) was obtained at $1.0 \mathrm{mg} \mathrm{L}^{-1} \mathrm{TDZ}$ and $1.5 \mathrm{mg} \mathrm{L}^{-1}$ BAP, respectively. However, in the presence of TDZ was observed the smaller shoots. The use of $2.0 \mathrm{mg} \mathrm{L}^{-1}$ IBA within activated charcoal $(A C)$ promoted the highest percentage of rooting (about $60.0 \%$ ) and number of adventitious roots (2.5). The rooted shoots were transferred to greenhouse and successfully acclimatized.
\end{abstract}

Key words: micropropagation, Leguminosae, pata-de-vaca, cytokinins, auxin, activated charcoal.

\section{INTRODUÇÃO}

A família Leguminosae ou Fabaceae inclui cerca de 900 gêneros e 19 mil espécies, sendo a família de maior representatividade na Caatinga. Dentre seus gêneros, destaca-se o Bauhinia com aproximadamente 300 espécies, sendo que no Brasil ocorrem 91 delas, conhecidas comumente como mororó ou pata-de-vaca (VAZ\&TOZZI, 2005). Aespécie em estudo, B. cheilantha,

'Programa de Pós-graduação em Biotecnologia, Universidade Estadual de Feira de Santana (UEFS), 44036-336, Feira de Santana, BA, Brasil. E-mail: far_gutierrez@yahoo.com.br. Autor para correspondência.

"Programa de Pós-graduação em Botânica, UEFS, Feira de Santana, BA, Brasil.

IIIEmbrapa Mandioca e Fruticultura Tropical, Cruz das Almas, BA, Brasil.

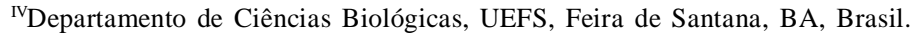


possui relevante aplicação madeireira, forrageira e como combustível (GUIMARÃES-BEELEN et al., 2006). Além disso, a planta tem grande importância medicinal, sendo sua parte aérea amplamente empregada nas práticas caseiras da medicina popular para o tratamento da diabetes (BARBOSA-FILHO et al., 2005). A espécie é propagada sexuadamente, contudo em suas sementes detectou-se a presença de dormência tegumentar, o que dificulta a rápida produção de plantas uniformes em campo (SEIFFERT, 2006).

Nesse contexto a micropropagação pode ser uma alternativa para a produção de mudas e conservação da espécie, uma vez que a aplicação desta técnica torna possível a propagação de mudas sadias, em qualquer época do ano, em tempo e espaço físico reduzido, com alta fidelidade genética, maior produtividade, uniformidade e desempenho no campo, contribuindo para reduzir a pressão extrativista em áreas nativas (GEORGE, 2008). No entanto, o sucesso de um protocolo de cultivo in vitro depende de vários fatores intrínsecos ao material propagativo e ao processo, como genótipo, estado fisiológico e manejo da planta matriz, idade e posição dos explantes, esterilização de subculturas, microambiente dentro dos frascos de cultura e balanço quantitativo dos reguladores vegetais, ficando sob responsabilidade do pesquisador controlá-los adequadamente durante toda a manipulação (COSTA et al., 2006).

Diante do exposto e em razão da ausência de relatos na literatura sobre a propagação assexuada da espécie, o presente trabalho objetivou estabelecer um protocolo de micropropagação para a espécie lenhosa B. cheilantha, através da indução de brotos adventícios em explantes de plântulas assépticas obtidas in vitro.

\section{MATERIAL E MÉTODOS}

As sementes de B. cheilanta foram coletadas pela EMBRAPA Semiárido, no Campo Experimental da Caatinga, município de Petrolina-PEe cedidas para o Laboratório de Cultura de Tecidos Vegetais da Universidade Estadual de Feira de Santana, onde foi realizado o trabalho. As sementes foram submetidas à escarificação mecânica (lixa $\mathrm{n}^{\circ} 03$ ), marcando o tegumento no lado oposto ao hilo(GOMES, 2009), em seguida foram desinfestadas em câmara de fluxo laminar, por imersão em etanol a $70 \%$ por um minuto, em solução de cloro ativo a $2,5 \%$ contendo duas gotas de detergente neutro por 15 minutos e, por fim, lavadas vezes sucessivas em água estéril. Dez sementes foram então inoculadas em placa de Petri contendo papel germitest previamente esterilizado, umedecido com água estéril e fechada com filme de polivinilcloreto (PVC). Após 72 horas da semeadura, quando as primeiras raízes haviam sido emitidas $(1,0 \mathrm{~cm}$ de comprimento), as plântulas foram transferidas para tubos de ensaio, contendo meio de cultura WPM (LLOYD \& McCOWN, 1980). Os explantes foram retirados das plântulas emergidas in vitro após 15 a 20 dias.

O meio de cultura utilizado para todas as fases do cultivo in vitro foi o WPM solidificado com $0,6 \%$ de ágar (Himedia ${ }^{\circledR}$ ) e suplementado com $3 \%$ de sacarose. $\mathrm{O} \mathrm{pH}$ foi ajustado para 5,7 $\pm 0,01$ antes da esterilização em autoclave a $121^{\circ} \mathrm{C}$ por $20 \mathrm{~min}$. Todas as culturas foram incubadas em sala de cultura mantida em $60 \%$ de umidade relativa, temperatura de $25 \pm 2^{\circ} \mathrm{C}$, sob fotoperíodo de $16 \mathrm{~h}$ e uma densidade de fluxo de fótons de $60 \mu \mathrm{mol} \mathrm{m}^{-2} \mathrm{~s}^{-1}$, fornecido por lâmpadas fluorescentes brancas. Na multiplicação in vitro, dois tipos de explantes foram utilizados (segmentos cotiledonar e nodal), os quais foram inoculados em diferentes concentrações de BAP, KIN ou TDZ $(0,0$; 0,$5 ; 1,0 ; 1,5$ e 2,0mg L $\left.\mathrm{m}^{-1}\right)$. O delineamento experimental utilizado foi inteiramente casualizado em esquema fatorial $2 \times 3 \times 5$, totalizando 30 tratamentos. Cada tratamento constou de cinco repetições, cada uma constituída por cinco tubos de ensaio, cada um dos quais contendo um explante. Após 30 dias da inoculação foram avaliadas as seguintes variáveis: porcentagem de explantes responsivos e número de brotos por explante. As mudas obtidas em meio de cultura WPM suplementado com $2,0 \mathrm{mg} \mathrm{L}^{-1}$ BAP, medindo entre 2,0 e 5,0 centímetros de comprimento foram transferidas para um meio de enraizamento suplementado com diferentes concentrações de AIB $\left(0,0 ; 0,5 ; 1,0\right.$ e $\left.2,0 \mathrm{mg} \mathrm{L}^{-1}\right)$ e carvão ativado $(0,0 ; 1,0 \mathrm{e}$ $\left.2,0 \mathrm{~g} \mathrm{~L}^{-1}\right)$. O delineamento experimental foi inteiramente casualizado, em esquema fatorial $4 \times 3$, totalizando 12 tratamentos. Cada tratamento constou de 15 repetições, cada uma composta por sete tubos de ensaio, cada um contendo um broto. Aos 45 dias após a inoculação foram avaliadas as seguintes variáveis: porcentagem de enraizamento, número de raízes adventícias por broto e comprimento da maior raiz $(\mathrm{cm})$.

No período de aclimatização, 60 plantas enraizadas in vitro foram transplantadas para sacos de polietileno contendo terra vegetal, sendo cobertas individualmente com garrafas pet de $1 \mathrm{~L}$ e mantidas sob sombrite $30 \%$. Durante esse período, a tampa da garrafa pet foi desenroscada no $7^{\circ}$ dia e retirada no $16^{\circ}$, sendo a garrafa removida no $30^{\circ} \mathrm{dia}$. As plantas foram regadas diariamente com água durante esse período, pela manhã. Aos 30 dias após o transplante avaliou-se a porcentagem de sobrevivência das mudas.

Ciência Rural, v.41, n.2, fev, 2011. 
Os dados obtidos foram submetidos à análise de variância (ANAVA) e as médias comparadas pelo teste de Tukey, com nível de significância de 5\% para os fatores qualitativos e ajustes usando as equações de regressão polinomial para os fatores quantitativos. A análise foi realizada com o software SISVAR(FERREIRA, 2008).

\section{RESULTADOS E DISCUSSÃO}

Para a variável porcentagem de explantes responsivos, a única interação significativa $(P \leqslant 0,01)$ foi a dupla (tipo de explante $\mathrm{x}$ concentração de citocinina), enquanto que para a variável número de brotos, houve significância $(\mathrm{P} \leqslant 0,01)$ para a interação tripla. Para o segmento nodal constatou-se uma taxa responsiva superior ao segmento cotiledonar, independente do tipo e concentração dos reguladores testados. A maior capacidade organogênica observada $(97,3 \%)$ ocorreu quando o segmento nodal foi inoculado em meio de cultura acrescido da maior concentração dos reguladores testados $\left(2,0 \mathrm{mg} \mathrm{L}^{-1}\right)$ (Tabela 1). A taxa de explantes responsivos encontrado para o segmento cotilenodar de B. cheilanta foi semelhante ao reportado por NAYAK et al. (2007), no qual uma média inferior a $56 \%$ foi observada para o segmento cotiledonar de Aegle marmelos (L.) Corr., independente da concentração de BAP ou KIN adicionada ao meio de cultura MS.

O segmento nodal emitiu maior número de brotos $(4,3)$ em meio de cultura suplementado com $1,0 \mathrm{mg} \mathrm{L}^{-1}$ de TDZ, formando 1,6 vezes mais brotos que a maior média observada em segmento cotilenodar $(2,6)$ nas mesmas condições (Tabela 2). Apesar do TDZ ter proporcionado um maior número de brotos, estes se

Tabela 1 - Porcentagem de explantes responsivos de $\boldsymbol{B}$. cheilantha, em meio de cultura WPM em função da concentração dos reguladores de crescimento testados e do tipo de explante (SC-segmento cotiledonar e SN-segmento nodal).

\begin{tabular}{lcc}
$\begin{array}{l}\text { Concentração dos } \\
\text { reguladores }\left(\mathrm{mg} \mathrm{L}^{-1}\right)\end{array}$ & \multicolumn{2}{c}{-----Explantes------- } \\
& $\mathrm{SC}$ & $\mathrm{SN}$ \\
\hline 0,0 & $62,67 \mathrm{~b}$ & $86,67 \mathrm{a}$ \\
0,5 & $44,00 \mathrm{~b}$ & $94,67 \mathrm{a}$ \\
1,0 & $56,00 \mathrm{~b}$ & $94,67 \mathrm{a}$ \\
1,5 & $51,00 \mathrm{~b}$ & $96,00 \mathrm{a}$ \\
2,0 & $56,33 \mathrm{~b}$ & $97,33 \mathrm{a}$ \\
\hline
\end{tabular}

Médias seguidas pela mesma letra, na mesma linha, não diferem estatisticamente entre si ao nível de $1 \%$ de probabilidade pelo teste de Tukey encontraram hiperídricos. O resultado encontrado foi superior ao reportado para B. vahlii Wight \& Arnott, em que na concentração igual de TDZ o número médio de brotos obtidos foi de 0,9/segmento nodal (DHAR \& UPRETI, 1998).

As citocininas são conhecidas por estimular ou inibir processos fisiológicos e dentre elas o BAP tem sido o mais indicado para promover a proliferação de partes aéreas e indução de gemas adventícias in vitro (GRATTAPAGLIA \& MACHADO, 1998), como evidenciado neste trabalho (Tabela 2). Os resultados encontrados para $\boldsymbol{B}$. cheilantha estão de acordo com os de BALARAJU et al. (2008), em que a formação de brotos por explante de Vitex agnus-castus L. foi superior em meio de cultura suplementado com BAP ao invés do incremento com KIN, assim como em Metrosideros excelsa Gaertn. (IAPICHINO \& AIRÒ, 2008). Contudo, em Stryphnodendron adstringens (Mart.) Coville, à medida que se aumentou a concentração de KIN no meio de cultura, o número de brotos formados a partir do segmento nodal foi favorecido, sendo registrada uma melhor resposta (3,0 brotos/explante) quando se utilizou $5,0 \mathrm{mg} \mathrm{L}^{-1}$ de KIN (NICIOLI et al., 2008). Para todas as variáveis analisadas, durante a etapa de enraizamento in vitro observou-se efeito significativo $(\mathrm{P} \leqslant 0,01)$ da interação dupla (concentrações de AIB x carvão ativado), sendo que o valor máximo estimado $(63,7 \%)$ da taxa de enraizamento tendeu a ocorrer quando se adicionou $1,7 \mathrm{mg} \mathrm{L}^{-1}$ de AIB ao meio de cultura, na ausência de carvão ativado. Concentrações do regulador superior a esta tenderam a desfavorecer a formação de raízes em B. cheilantha. Esse modelo matemático explica 98,0\% de toda a variação dos pontos no experimento (Figura 1A).

Enquanto as citocininas promovem divisão celular nas partes aéreas e raízes, as auxinas atuam no alongamento celular, sobretudo na promoção de raízes laterais e adventícias (TAIZ \& ZEIGER, 2009), sendo esta influência observada para B. cheilantha, na qual as menores taxas de enraizamento (cerca de 20\%) ocorreram na ausência de reguladores vegetais no meio de cultura (Figura 1A). No entanto, em culturas de Alibertia edulis (Rich.) A. Rich. ex DC. e Asparagus racemosus Willd. (SILVA et al., 2008; BOPANA \& SAXENA, 2008), mantidas em meio de cultura sem regulador vegetal, os níveis endógenos de auxinas não foram suficientes para promover a rizogênese. Segundo SOUZA \& PEREIRA (2007), o processo de indução e iniciação de raízes adventícias é regulado pela relação quantitativa entre os níveis de auxina e citocinina na planta, sendo esses teores endógenos variantes para cada genótipo. 
Tabela 2 - Número de brotos obtidos a partir de segmento cotiledonar (SC) e segmento nodal (SN) de B. cheilantha, em meio de cultura WPM com diferentes tipos e concentrações de citocininas.

\begin{tabular}{|c|c|c|c|c|c|c|}
\hline \multirow{2}{*}{ Explantes } & \multirow{2}{*}{ Citocinina } & \multicolumn{5}{|c|}{ 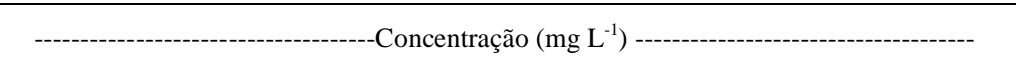 } \\
\hline & & 0,0 & 0,5 & 1,0 & 1,5 & 2,0 \\
\hline \multirow[t]{3}{*}{$\mathrm{SC}$} & KIN & $1,0 \mathrm{a}$ & $0,68 \mathrm{~b}$ & $1,12 \mathrm{ab}$ & $0,92 \mathrm{a}$ & $0,96 \mathrm{a}$ \\
\hline & BAP & $0,96 \mathrm{a}$ & $0,48 \mathrm{~b}$ & $0,68 \mathrm{~b}$ & $1,33 \mathrm{a}$ & $0,78 \mathrm{a}$ \\
\hline & TDZ & $1,00 \mathrm{a}$ & $2,60 \mathrm{a}$ & $1,80 \mathrm{a}$ & $1,29 \mathrm{a}$ & $1,32 \mathrm{a}$ \\
\hline \multirow[t]{3}{*}{ SN } & KIN & $0,91 \mathrm{a}$ & $0,96 \mathrm{~b}$ & $0,96 \mathrm{~b}$ & $1,12 \mathrm{~b}$ & $1,00 \mathrm{~b}$ \\
\hline & BAP & $1,00 \mathrm{a}$ & $1,36 \mathrm{~b}$ & $1,64 \mathrm{~b}$ & $2,08 \mathrm{a}$ & $1,36 \mathrm{ab}$ \\
\hline & $\mathrm{TDZ}$ & $0,97 \mathrm{a}$ & $2,88 \mathrm{a}$ & $4,32 \mathrm{a}$ & $2,00 \mathrm{a}$ & $2,08 \mathrm{a}$ \\
\hline
\end{tabular}

Médias seguidas pela mesma letra, na mesma coluna, não diferem estatisticamente entre si, ao nível de $1 \%$ de probabilidade pelo teste de Tukey.

As porcentagens de enraizamento encontradas para $\boldsymbol{B}$. cheilantha foram superiores as reportadas em cultura de Prunus salicina Lindl. inoculadas em meio de cultura $1 / 2$ MS utilizando concentrações mais altas $\left(3,0 \mathrm{mg} \mathrm{L}^{-1}\right)$ de AIB, $43,3 \mathrm{e}$ $50,0 \%$ para 'Shiro' e 'Early Golden', respectivamente (CANLI \& TIAN, 2009). Em Parapiptadenia rigida (Benth.) Brenan (KIELSE et al., 2009), foi constatada taxa de enraizamento de $15 \%$ independente da concentração de AIB utilizada, enquanto que para Erythrina velutina Willd. a maior taxa de enraizamento (75\%) foi observada em $0,5 \mathrm{mg} \mathrm{L}^{-1}$ de AIB (COSTA et al., 2010).

Para o número de raízes adventícias dos brotos estima-se que a sua parte radicular tenha um aumento no número de raízes adventícias em

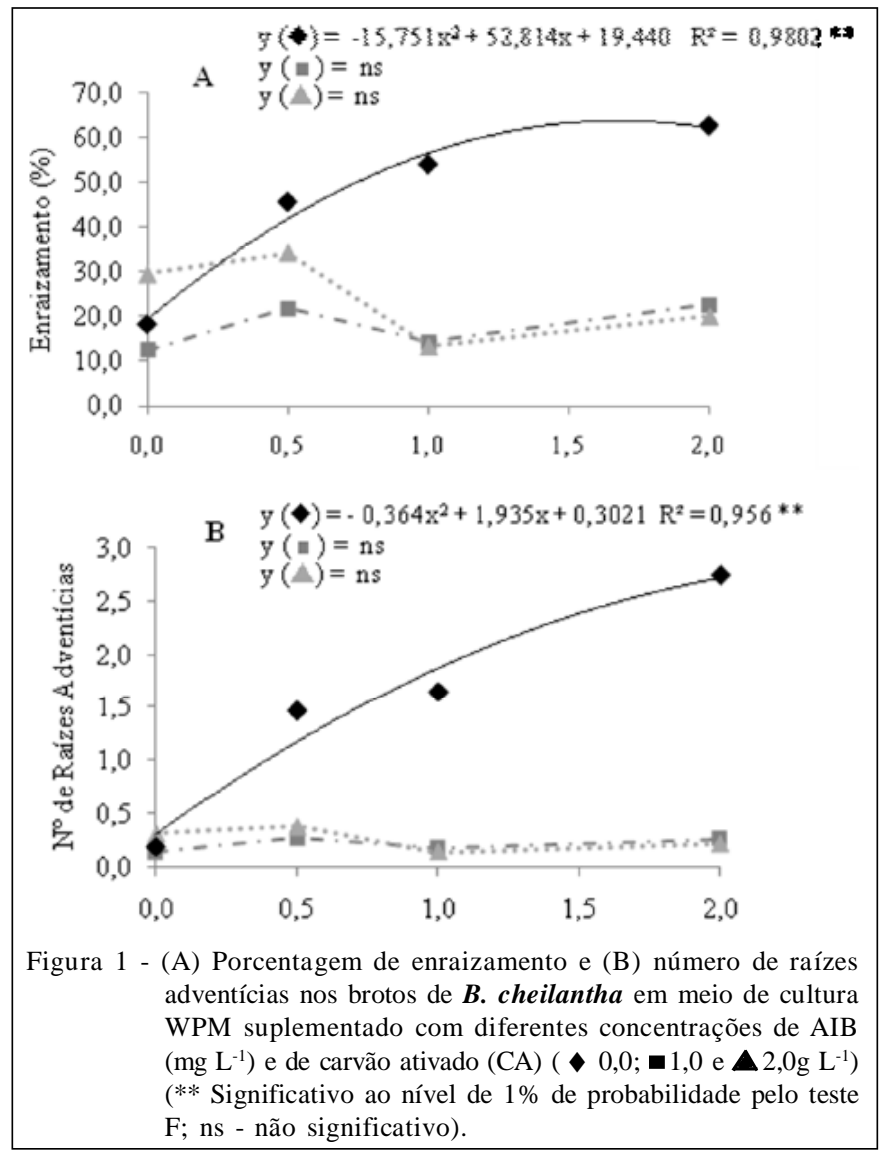

Ciência Rural, v.41, n.2, fev, 2011. 
concentrações crescentes de regulador, até a concentração estimada de $2,7 \mathrm{mg} \mathrm{L}^{-1}$ de $\mathrm{AIB}$, onde se atingiu o maior número estimado de raízes adventícias $(2,9)$ na ausência de carvão ativado. A adição de carvão ativado ao meio de cultura é utilizado no intuito de otimizar o crescimento e o desenvolvimento celular nas diferentes fases da cultura de tecidos (VIEITEZ et al., 2009), contudo, para B. cheilantha, nas concentrações de carvão ativado testadas não se observou efeito favorável para a variável em análise, independente da concentração de regulador utilizada (Figuras 1B).

$\mathrm{O}$ número de raízes adventícias por broto de $\boldsymbol{B}$. cheilantha foi superior quando comparada a média de 0,5 em culturas de $\boldsymbol{P}$. rigida, independente da concentração de AIB adicionada ao meio de cultura (KIELSE et al., 2009) e, inferior quando comparada a média de 4,3 raízes adventícias/broto em culturas de Searsia dentata F.A. Barkely, em meio acrescido de 2,0mg L ${ }^{-1}$ de AIB (PRAKASH \& STADEN, 2008).

Aos 30 dias de aclimatização, o percentual de sobrevivência de $\boldsymbol{B}$. cheilantha em casa-devegetação foi de $86 \%$, o que permite inferir que o protocolo de regeneração in vitro estabelecido é eficiente, visto que várias lenhosas têm baixo percentual de sobrevivência quando transferidas para o ambiente ex vitro (ZIV \& CHEN, 2008).

\section{CONCLUSÃO}

A propagação in vitro de $\boldsymbol{B}$. cheilantha é possível utilizando-se o segmento nodal como fonte de explante, em meio de cultura WPM suplementado com 2,0mg L-1 de BAP; a resposta da citocinina BAP é superior à KIN e TDZ, na etapa de multiplicação da espécie. $\mathrm{O}$ enraizamento pode ser feito na ausência de carvão ativado na presença de $2,0 \mathrm{mg} \mathrm{L}^{-1}$ de AIB.

\section{REFERÊNCIAS}

BALARAJU, K. et al. Micropropagation of Vitex agnus-castus, (Verbenaceae) - a valuable medicinal plant. In Vitro Cellular and Developmental Biology - Plant, Wallingford, v.44, n.5, p.436-441, 2008. Disponível em: <http://www.springerlink.com/ content/6187833243014583/fulltext.pdf $>$. Acesso em: 30 nov. 2010. doi: $10.1007 / \mathrm{s} 11627-008-9155-9$.

BARBOSA-FILHO, J.M. et al. Plants and their active constituents from South, Central, and North America with hypoglycemic activity. Revista Brasileira de Farmacognosia, João Pessoa, v.15, n.4, p.392-413, 2005. Disponível em: <http://www.scielo.br/ $\mathrm{pdf} / \mathrm{rbfar} / \mathrm{v} 15 \mathrm{n} 4 / \mathrm{a} 20 \mathrm{v} 15 \mathrm{n} 4 . \mathrm{pdf}>$. Acesso em: 30 nov. 2010. doi: 10.1590/S0102-695X2005000400021.

BOPANA, N.; SAXENA, S. In vitro propagation of a high value medicinal plant: Asparagus racemosus Willd. In Vitro Cellular and Developmental Biology - Plant, Wallingford, v.44, n.6, p.525-532, 2008. Disponível em: <http://www.springerlink.com/ content/6g5ph22gr2240032/fulltext.pdf $>$. Acesso em: 30 nov. 2010. doi: 10.1007/s11627-008-9137-y.

CANLI, F.A.; TIAN, L. Regeneration of adventitious shoots from mature stored cotyledons of japanese plum (Prunus salicina Lind.). Scientia Horticulturae, Amsterdam, v.120, n.1, p.6469, 2009. Disponível em: <http://www.sciencedirect.com/ science?_ob=MImg\&_imagekey=B 6TC3-4TRHC92-3$5 \&$ _cdi $=5159 \&$ _user $=686342 \&$ \&pii $=$ S0304423808004019\&_o rigin $=$ search \&_zone $=$ rslt_list_item\&_coverDate $=03 \% 2 \mathrm{~F} 03 \% 2 \mathrm{~F} 2$ $009 \&$ \& $\mathrm{k}=998799998 \& \mathrm{w} \mathrm{ch} \mathrm{p}=\mathrm{d} \mathrm{G} \mathrm{L} \mathrm{b} \mathrm{V} \mathrm{t} \mathrm{b} \mathrm{-}$ zSkzV\&md5 =e0b25b5c63069044ccb0c6e1830cde11\&ie $=/$ sdarticle.pdf $>$. Acesso em: 30 nov. 2010. doi:10.1016/ j.scienta.2008.09.017.

COSTA, GM. et al. Propagação in vitro de Erythrina velutina. Ciência Rural, Santa Maria, v.40, n.5, p.1090-1096, 2010. Disponível em: <http://www.scielo.br/pdf/cr/v40n5/a592cr2445.pdf >. Acesso em: 30 nov. 2010. doi: 10.1590/S0103-84782010005000084.

COSTA, M.A.P.C. et al. Morfogênese in vitro. In: SOUZA, A.S.; JUNGHANS, T.G. Introdução à micropropagação de plantas. Cruz das Almas: EMBRAPA Mandioca e Fruticultura Tropical, 2006. p.115-130.

DHAR, U.; UPRETI. J. In vitro regeneration of a mature leguminous liana (Bauhinia vahlii Wight \& Arnott). Plant Cell Reports, Berlin, v.18, n.7-8, p.664-669, 1998. Dsiponível em: <http://www.springerlink.com/content/jpm832vcyqnuhh56/ fulltext.pdf $>$. Acesso em: 30 nov. 2010.

FERREIRA, D.F. Sisvar: um programa para análises e ensino de estatística. Revista Científica Symposium, Lavras, v.6, n.2, p.36-41, 2008. Disponível em: <http://www.fadminas.org.br/ symposium/>. Acesso em: 30 nov. 2010.

GEORGE, E.F. Plant tissue culture procedure - Background. In: GEORGE, E.F. et al. (Ed.). Plant propagation by tissue culture. 3.ed. Dordrecht : Springer, 2008. V.1, p.1-28.

GUIMARÃES-BEELEN, P.M. et al. Characterization of condensed tannins from native legumes of the Brazilian northeastern semi-arid. Scientia Agricola, Piracicaba, v.63, n.6, p.522-528, 2006. Disponível em: <http://www.scielo.br/ pdf/sa/v63n6/a02v63n6.pdf>. Acesso em: 30 nov. 2010. doi: 10.1590/S0103-90162006000600002.

GOMES, H.L.R. Caracterização fisiológica da germinação de sementes de Bauhinia cheilantha (Bong.) Steud. 2009. 33f. Monografia (Graduação em Ciências Biológicas) Universidade Estadual de Feira de Santana, Feira de Santana, Ba.

GRATTAPAGLIA, D.; MACHADO, M.A. Micropropagação. In: TORRES, A.C. et al. Cultura de tecidos e transformação genética de plantas. Brasília: CBAB-EMBRAPA, 1998. p. $183-260$.

IAPICHINO, G.; AIRÒ, M. Micropropagation of Metrosideros excelsa. In Vitro Cellular and Developmental Biology Plant, Wallingford, v.44, n.4, p.330-337, 2008. Disponível em: <http://www.springerlink.com/content/2kv0k8n67367655h/ fulltext.pdf>. Acesso em: 30 nov. 2010. doi: 10.1007/s11627008-9127-0.

LLOYD, G.; McCOWN, B. Use of microculture for production and improvement of Rhododendron spp. HortScience, Alexandria, v.15, n.3, p.416-417, 1980. 
KIELSE, P. et al. Regeneração in vitro de Parapiptadenia rigida. Ciência Rural, Santa Maria, v.39, n.4, p.1088-1094, 2009. Disponível em: <http://www.scielo.br/pdf/cr/v39n4/ a152cr1223.pdf >. Acesso em: 30 nov. 2010. doi: 10.1590/ S0103-84782009005000046.

NAYAK, P. et al. High frequency plantlet regeneration from cotyledonary node cultures of Aegle marmelos (L.) Corr. In Vitro Cell Developmental Biology - Plant, Wallingford, v.43, n.3, p.231-236, 2007. Disponível em: <http:// www.springerlink.com/content/63628r2197067645/ fulltext.pdf>. Acesso em 30 nov. 2010. doi: 10.1007/s11627006-9013-6.

NICIOLI, P.M. et al. Ajuste do processo de micropropagação de barbatimão. Ciência Rural, Santa Maria, v.38, n.3, p.685689, 2008. Disponível em: <http://www.scielo.br/pdf/cr/v38n3/ a14v38n3.pdf $>$. Acesso em: 30 nov. 2010. doi: 10.1590/ S0103-84782008000300014.

PRAKASH, S.; STADEN, J.V. Micropropagation of Searsia dentata. In Vitro Cellular and Developmental Biology Plant, Wallingford, v.44, n.4, p.338-341, 2008. Disponível em: <http://www.springerlink.com/content/e0u222887m156611/ fulltext.pdf>. Acesso em: 30 nov. 2010. doi: 10.1007/s11627008-9129-y.

SEIFFERT-SANINE, M. Estudos de alguns aspectos de germinação e bioquímicos de sementes de Bauhinia cheilantha (Bong.) Steud., sob diferentes condições de armazenamento. 2006. 69f. Tese (Doutorado em Ciências Biológicas) - Universidade Estadual Paulista "Júlio Mesquita Filho" - Instituto de Biociências, Botucatu, SP.
SILVA, F.A.B. et al. Micropropagation of Alibertia edulis Rich. Brazilian Archives of Biology and Technology, Curitiba, v.51, n.6, p.1103-1114, 2008. Disponível em: <http:// www.scielo.br/pdf/babt/v51n6/04.pdf>. Acesso em: 30 nov. 2010. doi: $10.1590 / \mathrm{S} 1516-89132008000600004$.

SOUZA, A.V.; PEREIRA, A.M.S. Enraizamento de plantas cultivadas in vitro. Revista Brasileira de Plantas Medicinais, Botucatu, v.9, n.4, p.103-117, 2007. Disponível em: <http:// www.ibb.unesp.br/servicos/publicacoes/rbpm/pdf_v9_n4_2007/ artigo17_v9_n4.pdf>. Acesso em: 30 nov. 2010.

TAIZ, L.; ZEIGER, E. Fisiologia vegetal. 4.ed. Porto Alegre: Artmed, 2009. 819p.

VAZ, A.M.S.F; TOZZI, A.M.G.A. Sinopse de Bauhinia sect. Pauletia (Cav.) DC. (Leguminosae: Caesalpinioideae: Cercideae) no Brasil. Revista Brasileira de Botânica, São Paulo, v.28, n.3, p.477-491, 2005. Disponível em: <http://www.scielo.br/ pdf/rbb/v28n3/28999.pdf>. Acesso em: 30 nov. 2010. doi: 10.1590/S0100-84042005000300006.

VIEITEZ, A.M. et al. In vitro regeneration of the important North American oak species Quercus alba, Quercus bicolor and Quercus rubra. Plant Cell Tissue and Organ Culture, Netherland, v.98, n.2, p.135-145, 2009. Disponível em: <http:/ /www.springerlink.com/content/v3432031g3688323/ fulltext.pdf>. Acesso em: 30 nov. 2010. doi: 10.1007/s11240009-9546-6.

ZIV, M.; CHEN, J. The anatomy and morphology of tissue cultured plants. In: GEORGE, E.F. et al. (Ed). Plant propagation by tissue culture. 3.ed. Dordrecht: Springer, 2008. V.1, p.465-478. 